\title{
Environmental Impact Assessment of Transportation Networks with Degradable Links in an Era of Climate Change
}

\author{
Anna Nagurney \\ Department of Finance and Operations Management \\ Isenberg School of Management \\ University of Massachusetts \\ Amherst, Massachusetts 01003 \\ Qiang Qiang \\ Management Division \\ Pennsylvania State University \\ Graduate School of Professional Studies \\ Malvern, Pennsylvania 19355 \\ Ladimer S. Nagurney \\ Department of Electrical and Computer Engineering \\ University of Hartford \\ West Hartford, Connecticut 06117 \\ January 2008; revised June; August 2008 \\ International Journal of Sustainable Transportation (2010) 4: 154-171

\begin{abstract}
This paper proposes environmental impact assessment indices to evaluate the environmental effects of link capacity degradation in transportation (road) networks. The indices are applicable in the case of either user-optimizing or system-optimizing behavior. We also construct environmental link importance indicators that allow for the ranking of links in transportation networks in terms of their environmental importance, should they be removed/destroyed. Numerical transportation network examples illustrate the proposed quantitative environmental indicators and further substantiate that system-optimizing behavior does not necessarily lead to reduced emissions.
\end{abstract}

Key words: environmental assessment, transportation networks, climate change, network robustness, system-optimization, user-optimization, Bureau of Public Roads link cost functions, degradable links, vulnerability analysis 


\section{Introduction}

According to the American Society of Civil Engineers (2005), the degradation of transportation networks due to poor maintenance, natural disasters, deterioration over time, in addition to unforeseen attacks, leads to estimates of $\$ 94$ billion in the United States in terms of needed repairs for roads alone. Moreover, in a new era of climate change, it is expected, as documented in numerous studies (cf. National Assessment Team (2001), US Department of Transportation (2002), Smith and Levasseur (2002), Zimmerman (2003), Arkell and Darch (2006), Schulz (2007)), that the degradation of critical infrastructure, including transportation networks, can be expected to increase. At the same time, emissions generated through transportation are some of the biggest contributors to climate change and global warming. According to a US EPA (2006) report, the transportation sector in 2003 accounted for $27 \%$ of the total greenhouse gas emissions in the US and the increase in this sector was the largest of any in the period 1990 - 2003. In addition, the energy use due to transportation is expected to increase by $48 \%$ between 2003 and 2025, even with modest improvements in the efficiency of vehicular engines.

Indeed, the impact of the degradation of transportation network infrastructure is being increasingly documented. The American Society of Civil Engineers (2005) further reports that substandard road conditions in the United States cost its motorists $\$ 54$ billion in repairs and operating costs each year. The degradation of roads not only impacts motorists but also freight. A report by the US Department of Transportation Federal Highway Administration (2006a) notes that the US is experiencing a freight capacity crisis that threatens US economic productivity. As reported in Jeanneret (2006), the American Road \& Transportation Builders Association states that nearly $75 \%$ of US freight is carried in the US on highways and bottlenecks now cause truckers 243 million hours of delay annually with an estimated associated cost of $\$ 8$ billion. Such delays result in additional generated emissions that, in turn, further impact negatively the environment and affect the deterioration of the critical road infrastructure creating a vicious cycle.

In this paper, we explore the assessment of the environmental impact of the degradation of transportation network infrastructure in the form of roads. The research reported in this paper builds on our work on network efficiency/performance measurement and vulnerability and robustness analysis (cf. Nagurney and Qiang (2007a, b, c)). However, unlike our previous research, which focused principally on the identification of the critical network components, that is, those nodes and links, or combinations thereof, such that their removal would impact the network efficiency the most, here we are concerned with the total emissions generated as a consequence of link capacity deterioration. In addition, we consider not 
only user-optimizing (U-O) behavior but also system-optimizing (S-O) behavior (see, e.g., Beckmann, McGuire, and Winsten (1956), Dafermos and Sparrow (1969), and Nagurney (1999, 2000a) and the references therein). Although the research on the topic of transportation network vulnerability and robustness analysis has been growing (cf. Berdica (2002), Sakakibara, Kajitani, and Okada (2004), Scott et al. (2006), Taylor, Sekhar, and D'Este (2006), Murray and Grubesic (2007), Nagurney and Qiang (2007a, b, c, d), Jenelius (2007), among others), the investigation into environmental impact assessment indices that capture the effects on the environment of transportation network degradation has not been fully explored to-date. For example, Taylor and Anderson (1984) studied traffic flow patterns, emission and noise distributions of the 1976 Melbourne traffic network based on different user behaviors, including $\mathrm{U}-\mathrm{O}$ and $\mathrm{S}-\mathrm{O}$ behaviors. However, the authors mainly focused on comparing the different traffic flow patterns and emission and noise levels (see also, Wigan (1975)). In this paper, we go a step further, in that we explore the impact of transportation network capacity degradation on network emissions and alternative travel behaviors.

Moreover, the identification of link importance from an environmental perspective has not been adequately determined. Finally, given the existence of emission paradoxes (cf. Nagurney (2000b)) it is essential to consider both U-O and S-O behaviors in evaluating potential impacts on the environment of transportation network degradation.

This paper is organized as follows. In Section 2, we briefly recall the well-known useroptimal (U-O) and system-optimal (S-O) transportation network conditions corresponding, respectively, to Wardrop's first and second principles of travel behavior (cf. Wardrop (1952); see also, e.g., Beckmann, McGuire and Winsten (1956), Dafermos and Sparrow (1969), Smith (1979), Dafermos (1980), Sheffi (1985), and Nagurney (2000a)). Recall (cf. Dafermos and Sparrow (1969)) that a flow pattern is said to be U-O if all used paths, that is, those with positive flow, connecting each origin/destination pair of nodes in a network have user travel costs that are equal and minimal. A flow pattern is said to be $\mathrm{S}-\mathrm{O}$ if it minimizes the total cost in a network, in which case, the Kuhn-Tucker optimality conditions (cf. Bazaraa, Sherali, and Shetty (1993)) coincide with the statement that all used paths connecting each origin/destination pair of nodes have marginal total costs that are equal and minimal.

In Section 2, we propose the environmental assessment index that can be used to assess the environmental robustness of transportation networks in the case of either $\mathrm{U}-\mathrm{O}$ or S-O travel behavior. In addition, we introduce a link importance indicator that allows one to determine the ranking of the links in terms of their impact on the environment in case they are removed/destroyed. 
In Section 3, we present numerical transportation network examples for which we compute the environmental impact assessment indicators in the case of degradable links under U-O and S-O behaviors.

In Section 4, we present a summary of the results along with our conclusions and suggestions for future research.

\section{The Environmental Impact Assessment Index and Link Importance Identifi- cation for Transportation Networks Under Distinct Travel Behaviors}

In this Section, we present the environmental impact assessment index for transportation networks in the case of degradable links and under distinct travel behaviors. The user link cost functions are assumed to be of the Bureau of Public Roads (BPR) (1964) functional form in which the practical link capacity is incorporated. In addition, we propose a means by which the importance of a link can be identified from an environmental perspective. The links can then be ranked in terms of the impact on the environment if the link is destroyed/removed or, equivalently, if the link deteriorates to such a degree that it is not usable. Due to the space limit here, we briefly recall the U-O and S-O conditions for transportation network models with fixed demands. For details of the notation for transportation network models, please refer to Chapter 4 of the book by Nagurney (1999) and the references therein.

We assume that the conservation of flow conditions hold for each origin/destination (O/D) pair and between links and paths. We also assume that the user cost on a path is equal to the sum the of user costs on links that make up the path. Furthermore, link cost functions are assumed to be continuous and monotonically increasing.

Given the above assumptions, recall that under the user-optimization problem, all used paths connecting an O/D pair have equal and minimal user travel costs whereas for the system-optimization problem in which a central controller seeks to minimize the total cost in a transportation network system, all used paths connecting an O/D pair have equal and minimal marginal total costs.

In this paper, we consider user link cost functions, denoted by $c_{a}$ for link $a$, known as BPR functions, given by

$$
c_{a}\left(f_{a}\right)=t_{a}^{0}\left[1+k\left(\frac{f_{a}}{u_{a}}\right)^{\beta}\right], \quad \forall a \in L,
$$

where $L$ is the the set of directed links in a transportation network; $f_{a}$ is the flow on link $a ; u_{a}$ is the "practical" capacity on link $a$, which also has the interpretation of the level-of-service flow rate; $t_{a}^{0}$ is the free-flow travel time or cost on link $a ; k$ and $\beta$ are the model parameters and 
both take on positive values (Bureau of Public Roads (1964) and Sheffi (1985)). Typically, in applications, $k=.15$ and $\beta=4$. We use such values of these parameters in the numerical transportation network examples in Section 3.

The total cost on a link $a$, denoted by $\hat{c}_{a}$, is given by:

$$
\hat{c}_{a}=\hat{c}_{a}\left(f_{a}\right)=c_{a}\left(f_{a}\right) \times f_{a}=t_{a}^{0}\left[1+k\left(\frac{f_{a}}{u_{a}}\right)^{\beta}\right] \times f_{a}, \quad \forall a \in L .
$$

The total cost on a network, denoted by $T C$, is, hence, given by:

$$
T C=\sum_{a \in L} \hat{c}_{a}\left(f_{a}\right)
$$

where the link flows $f$ must satisfy the nonnegativity and conservation of flow conditions.

\subsection{Environmental Emissions}

Alexopoulos and Assimacopoulos (1993) have argued that carbon monoxide (CO), since it is emitted exclusively by vehicular traffic, is important as an indicator for the level of atmospheric pollution generated by such traffic. Moreover, it has been shown that CO is the most significant pollutant among all other types of vehicle emissions (cf. US Department of Transportation Federal Highway Administration (2006b)). Furthermore, it is noted that other pollutants that are related to congestion exhibit similar behavior (cf. Hizir (2006) and the California Air Resources Board (2005)). Similar arguments have also been used by, among others, Yin and Lawphongpanich (2006) (see also Rilett, and Benedek (1994), Wallace et al. (1998), and Sugawara and Neimeier (2002)). In particular, we note that Yin and Lawphongpanich (2006) utilized the following function to estimate vehicular CO emissions, which was adopted from the macroscopic relationship model of Wallace et al. (1998):

$$
e_{a}\left(f_{a}\right)=0.2038 \times c_{a}\left(f_{a}\right) \times e^{0.7962 \times\left(\frac{l_{a}}{c_{a}\left(f_{a}\right)}\right)},
$$

where $l_{a}$ denotes the length of link $a$ and $c_{a}$ corresponds to the travel time (in minutes) to traverse link $a$. The length $l_{a}$ is measured in kilometers for each link $a \in L$ and the emissions are in grams per hour. The expression for total CO emissions on a link $a$, denoted by $\hat{e}_{a}\left(f_{a}\right)$, is then given by:

$$
\hat{e}_{a}\left(f_{a}\right)=e_{a}\left(f_{a}\right) \times f_{a}
$$

The total emissions of $\mathrm{CO}$ generated on a network is denoted by TE and is, hence:

$$
\mathrm{TE}=\sum_{a \in L} \hat{e}_{a}\left(f_{a}\right)
$$


In this paper, we will be interested in determining TE evaluated at the U-O solution and at the S-O solution for given networks as the capacity of the links on the networks degrades.

We note that Hizir (2006) in his thesis derived total emission functions in the case of multiple pollutants, notably, CO2 and NOx, that are similar to the above total emission functions, except with differing parameters. Moreover, the emission functions also included link capacities as is the case of (4) with travel cost functions given by (1). A similar approach is taken by Akcelik and Besley (2003) in the case of CO, CO2, HC, and NOx.

\subsection{The Environmental Impact Assessment Index for Transportation Networks}

We now propose an index based on the relative total emissions generated that assesses the environmental impact of the degradation of a transportation network based on the two behavioral solution concepts, namely, under the user-optimizing flow pattern, denoted by $\mathrm{TE}_{U-O}$, and the system-optimizing flow pattern, denoted by $\mathrm{TE}_{S-O}$. In particular, $\mathrm{TE}_{U-O}$ denotes the total emissions on the network as given by expression (6), where the vector $f$ is the solution to the user-optimizing (or transportation network equilibrium) conditions. On the other hand, $\mathrm{TE}_{S-O}$ represents the total emissions generated on the network according to expression (6), but now evaluated at the flow pattern given by the solution to the S-O problem. We believe that the total emissions generated is an appropriate measure since it represents the total emissions to society associated with travel on transportation networks. Moreover, as the links degrade and the practical capacity of links decreases the total emissions are expected to increase and, hence, the relative total emissions of a transportation network reflect the environmental impact.

The environmental impact assessment index for a transportation network $G$ with the vector of demands $d$, the vector of user link cost functions $c$, and the vector of link capacities $u$ is defined as the relative total emission increase under a given uniform capacity retention ratio $\gamma(\gamma \in(0,1])$ so that the new capacities (cf. (2)) are given by $\gamma u$. Let $c$ denote the vector of BPR user link cost functions and let $d$ denote the vector of $\mathrm{O} / \mathrm{D}$ pair travel demands. The mathematical definition of the environmental impact assessment index under the user-optimizing flow pattern, denoted by $\mathrm{EI}_{U-O}^{\gamma}$, is then:

$$
\mathrm{EI}_{U-O}^{\gamma}=\mathrm{EI}_{U-O}(G, c, d, \gamma, u)=\frac{\mathrm{TE}_{U-O}^{\gamma}-\mathrm{TE}_{U-O}}{\mathrm{TE}_{U-O}}
$$

where $\mathrm{TE}_{U-O}$ and $\mathrm{TE}_{U-O}^{\gamma}$ are the total emissions generated under the user-optimizing flow pattern with the original capacities and the remaining capacities (i.e., $\gamma u$ ), respectively.

The mathematical definition of the environmental impact assessment index under the 
system-optimizing flow pattern, denoted by $\mathrm{EI}_{S-O}^{\gamma}$, is:

$$
\mathrm{EI}_{S-O}^{\gamma}=\mathrm{EI}_{S-O}(G, c, d, \gamma, u)=\frac{\mathrm{TE}_{S-O}^{\gamma}-\mathrm{TE}_{S-O}}{\mathrm{TE}_{S-O}},
$$

where $\mathrm{TE}_{S-O}$ and $\mathrm{TE}_{S-O}^{\gamma}$ are the total emissions generated at the system-optimizing flow pattern with the original capacities and the remaining capacities (i.e., $\gamma u$ ), respectively.

For example, if $\gamma=.9$ this means that the user link cost functions given by (2) now have the link capacities given by $.9 u_{a}$ for $a \in L$; if $\gamma=.7$ then the link capacities become $.7 u_{a}$ for all links $a \in L$, and so on. Such changes also impact the emission functions (4) and (5).

From the above definition(s), a transportation network, under a given capacity retention/deterioration ratio $\gamma$ (and under either $\mathrm{S}-\mathrm{O}$ or $\mathrm{U}-\mathrm{O}$ travel behavior), is considered to be environmentally robust if the index $\mathrm{EI}^{\gamma}$ is low. This means that the relative total emissions do not change much and, hence, the transportation network may be viewed as being more robust, from an environmental perspective, than if the relative total emissions value is large.

\subsection{Link Importance Identification and Ranking}

The importance identification of network components is essential for planning, maintenance, security, as well as vulnerability analysis. As noted in the Introduction, Nagurney and Qiang (2007a, b, c) introduced a network efficiency measure that was based on U-O behavior and demonstrated that it outperformed several existing measures, including complex network measures, in identifying and ranking either links or nodes or combinations thereof (see also Schulz (2007)). Those papers also include extensive references on the topic. However, such a measure, since it is focused on efficiency, does not apply directly to environmental impact assessment and does not allow for S-O behavior. On the other hand, the environmental impact assessment indicators given by (7a) and (7b) capture the impact of alternative behaviors on the environment as the transportation network is subject to link capacity degradations. These indicators focus on uniform link capacity degradations where each link capacity denoted by $u_{a}$ for links $a \in L$ is degraded to $\gamma u_{a}$ for all $a \in L$ where $\gamma \in(0,1]$. One can also construct extensions of $(7 \mathrm{a})$ and $(7 \mathrm{~b})$ to handle non-uniform deterioration in link capacities where $\gamma$ is now replaced by $\tilde{\gamma}$ where $\tilde{\gamma}$ is a vector of link retention ratios. This concept motivates us to construct the following link importance indicators, which also build on the work of Nagurney and Qiang (2007a, b, c):

$$
\begin{aligned}
\mathrm{I}_{U-O}^{l} & =\frac{\mathrm{TE}_{U-O}(G-l)-\mathrm{TE}_{U-O}}{\mathrm{TE}_{U-O}} \\
\mathrm{I}_{S-O}^{l} & =\frac{\mathrm{TE}_{S-O}(G-l)-\mathrm{TE}_{S-O}}{\mathrm{TE}_{S-O}}
\end{aligned}
$$


where $\mathrm{I}_{U-O}^{l}$ denotes the importance indicator for link $l$ assuming $\mathrm{U}-\mathrm{O}$ behavior and $\mathrm{I}_{S-O}^{l}$ denotes the analogue under $\mathrm{S}-\mathrm{O}$ behavior; $\mathrm{TE}_{U-O}(G-l)$ denotes the total emissions generated under U-O behavior if link $l$ is removed from the network and $\mathrm{TE}_{S-O}(G-l)$ denotes the same but under S-O behavior. Note that a link may be, in effect, removed from a transportation network due to extreme events such as a bridge collapsing, a road becoming impassable, etc. Based on the specific values of (8a) and (8b) the links for a given transportation network can then be ranked. Clearly, the most important links should be maintained and secured at a higher level since their removal will have the largest environmental impact.

Obviously, to make a measure such as (8a) or (8b) applicable and well-defined, it is essential that after the elimination of a given link $l$ there is still a path/route available between each $\mathrm{O} / \mathrm{D}$ pair.

\section{Numerical Examples}

In this Section we explore the concepts described in Section 2 in the context of concrete numerical examples. In Section 3.1, we consider a transportation network from the more recent literature and in Section 3.2, we study the well-known Sioux Falls Network.

\subsection{The Yin and Lawphongpanich (2006) Network}

The topology of the first transportation network that we studied is depicted in Figure 1. This transportation network, but without capacity degradation, was proposed by Yin and Lawphongpanich (2006). There are two O/D pairs in the network: $w_{1}=(1,3)$ and $w_{2}=(2,4)$ with demands of $d_{w_{1}}=3000$ vehicles per hour and $d_{w_{2}}=3000$ vehicles per hour.

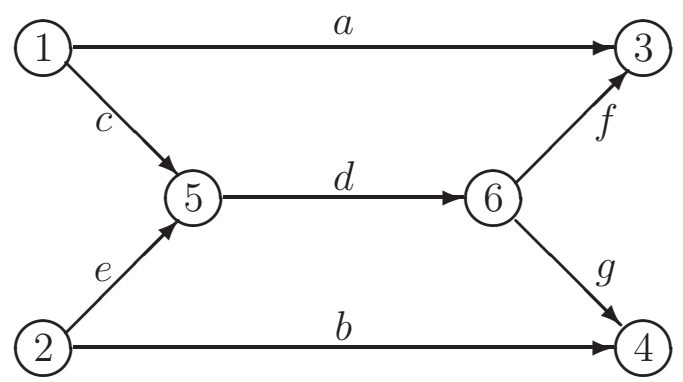

Figure 1: The Yin and Lawphongpanich (2006) Network

The user link cost functions, which here correspond to travel time in minutes, are of the 
BPR form given by (6) and are as follows:

$$
\begin{aligned}
& c_{a}\left(f_{a}\right)=8\left(1+.15\left(f_{a} / 2000\right)^{4}\right), \quad c_{b}\left(f_{b}\right)=9\left(1+.15\left(f_{b} / 2000\right)^{4}\right), \quad c_{c}\left(f_{c}\right)=2\left(1+.15\left(f_{c} / 2000\right)^{4}\right), \\
& c_{d}\left(f_{d}\right)=6\left(1+.15\left(f_{d} / 4000\right)^{4}\right), \quad c_{e}\left(f_{e}\right)=3\left(1+.15\left(f_{e} / 2000\right)^{4}\right), \quad c_{f}\left(f_{f}\right)=3\left(1+.15\left(f_{f} / 2500\right)^{4}\right), \\
& c_{g}\left(f_{g}\right)=4\left(1+.15\left(f_{g} / 2500\right)^{4}\right) .
\end{aligned}
$$

The lengths of the links, in kilometers, in turn, which are needed to compute the environmental emissions (cf. (4) - (6)) and constructed by Yin and Lawphongpanich (2006) are given by:

$$
l_{a}=8.0, \quad l_{b}=9.0, \quad l_{c}=2.0, \quad l_{d}=6.0, \quad l_{e}=3.0, \quad l_{f}=3.0, \quad l_{g}=4.0 .
$$

In Table 1 we present the U-O link flow solutions as the capacity ratio $\gamma$ changes in the range from zero to one. In Table 2 we report the corresponding S-O link flow solutions. Table 3 displays the total $\mathrm{CO}$ emissions generated under these two distinct behavioral assumptions and under the same capacity retention ratios $\gamma$. In addition, Table 3 also documents the two environmental impact assessment indices.

Table 1: U-O Solutions as Capacity Deteriorates - Link Flows for the Yin and Lawphongpanich (2006) Network

\begin{tabular}{|c|c|c|c|c|c|c|c|c|c|c|}
\hline $\operatorname{Link}$ & $\gamma=1$. & $\gamma=.9$ & $\gamma=.8$ & $\gamma=.7$ & $\gamma=.6$ & $\gamma=.5$ & $\gamma=.4$ & $\gamma=.3$ & $\gamma=.2$ & $\gamma=.1$ \\
\hline$a$ & 2514.99 & 2268.31 & 2038.30 & 1842.66 & 1699.60 & 1609.46 & 1559.85 & 1536.47 & 1527.82 & 1525.83 \\
$b$ & 2624.17 & 2365.60 & 2120.00 & 1905.80 & 1742.40 & 1635.32 & 1574.73 & 1545.75 & 1534.96 & 1532.47 \\
$c$ & 485.01 & 731.69 & 961.70 & 1157.34 & 1300.40 & 1390.54 & 1440.15 & 1463.53 & 1472.18 & 1474.17 \\
$d$ & 860.84 & 1366.09 & 1841.70 & 2251.44 & 2558.00 & 2755.23 & 2865.42 & 2917.78 & 2937.21 & 2941.70 \\
$e$ & 375.83 & 634.40 & 880.00 & 109.20 & 1257.60 & 1364.68 & 1425.27 & 1454.25 & 1465.04 & 1467.17 \\
$f$ & 485.01 & 731.69 & 961.70 & 1157.34 & 1300.40 & 1390.54 & 1440.14 & 1463.53 & 1472.18 & 1474.17 \\
$g$ & 375.83 & 634.40 & 880.00 & 1094.20 & 1257.60 & 1364.68 & 1425.27 & 1454.25 & 1465.04 & 1467.53 \\
\hline
\end{tabular}


Table 2: S-O Solutions as Capacity Deteriorates - Link Flows for the Yin and Lawphongpanich (2006) Network

\begin{tabular}{|c|c|c|c|c|c|c|c|c|c|c|}
\hline $\operatorname{Link}$ & $\gamma=1$. & $\gamma=.9$ & $\gamma=.8$ & $\gamma=.7$ & $\gamma=.6$ & $\gamma=.5$ & $\gamma=.4$ & $\gamma=.3$ & $\gamma=.2$ & $\gamma=.1$ \\
\hline$a$ & 1791.87 & 1701.73 & 1635.64 & 1589.96 & 1560.28 & 1542.34 & 1532.50 & 1527.85 & 1526.12 & 1525.72 \\
$b$ & 1848.60 & 1744.93 & 1666.79 & 1611.65 & 1575.26 & 1553.05 & 1540.81 & 1535.00 & 1532.84 & 1532.34 \\
$c$ & 1208.13 & 1298.27 & 1364.36 & 1410.04 & 1439.72 & 1457.67 & 1467.50 & 1472.15 & 1473.88 & 1474.28 \\
$d$ & 2359.53 & 2553.34 & 2697.57 & 2798.40 & 2864.46 & 2904.62 & 2926.69 & 2937.16 & 2941.04 & 2941.94 \\
$e$ & 1151.40 & 1255.07 & 1333.21 & 1388.35 & 1424.74 & 1446.95 & 1459.19 & 1465.00 & 1467.16 & 1467.66 \\
$f$ & 1208.13 & 1298.27 & 1364.36 & 1410.04 & 1439.72 & 1457.67 & 1467.50 & 1472.15 & 1473.88 & 1474.28 \\
$g$ & 1151.40 & 1255.07 & 1333.21 & 1388.35 & 1424.74 & 1446.95 & 1459.19 & 1465.00 & 1467.16 & 1467.66 \\
\hline
\end{tabular}

Table 3: Total Emissions Generated (grams/hour) and Environmental Impact Indicators for Varying Degradable Capacities for the Yin and Lawphongpanich (2006) Network

\begin{tabular}{|c|c|c|c|c|}
\hline$\gamma$ & $\mathrm{TE}_{U-O}^{\gamma}$ & $\mathrm{EI}_{U-O}^{\gamma}$ & $\mathrm{TE}_{S-O}^{\gamma}$ & $\mathrm{EI}_{S-O}^{\gamma}$ \\
\hline 1. & $26,744.62$ & .0000 & $27,140.19$ & .0000 \\
.9 & $27,336.24$ & .0221 & $27,565.00$ & .0157 \\
.8 & $27,982.55$ & .0463 & $28,045.61$ & .0334 \\
.7 & $28,820.11$ & .0776 & $28,753.98$ & .0595 \\
.6 & $30,291.05$ & .1326 & $30,162.84$ & .1114 \\
.5 & $33,874.37$ & .2666 & $33,758.30$ & .2438 \\
.4 & $45,033.94$ & .6839 & $44,970.11$ & .6570 \\
.3 & $88,964.12$ & 2.3364 & $88,943.63$ & 2.2772 \\
.2 & $355,639.84$ & 12.2976 & $355,636.28$ & 12.1037 \\
.1 & $5,351,015.00$ & 199.0782 & $5,351,016.50$ & 196.1621 \\
\hline
\end{tabular}

In Figure 2, we depict the ratio of $\mathrm{TE}_{U-O}^{\gamma}$ to $\mathrm{TE}_{S-O}^{\gamma}$. In Figure 3, we plot the environmental impact indicators under $\mathrm{U}-\mathrm{O}$ and $\mathrm{S}-\mathrm{O}$ behaviors. 


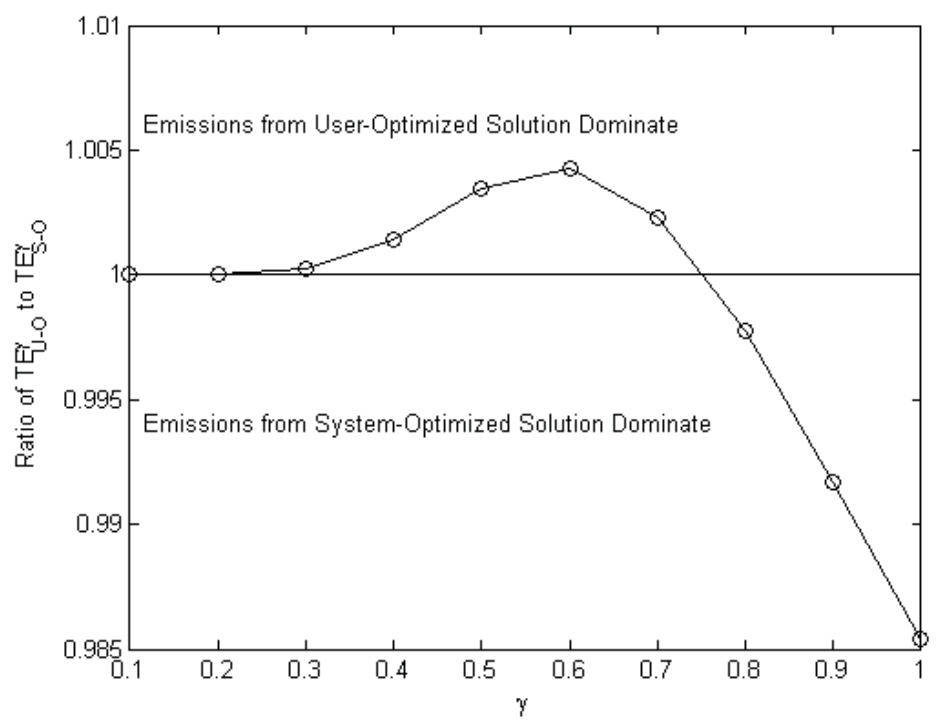

Figure 2: Ratio of $\mathrm{TE}_{U-O}^{\gamma}$ to $\mathrm{TE}_{S-O}^{\gamma}$ for the Yin and Lawphongpanich (2006) Network

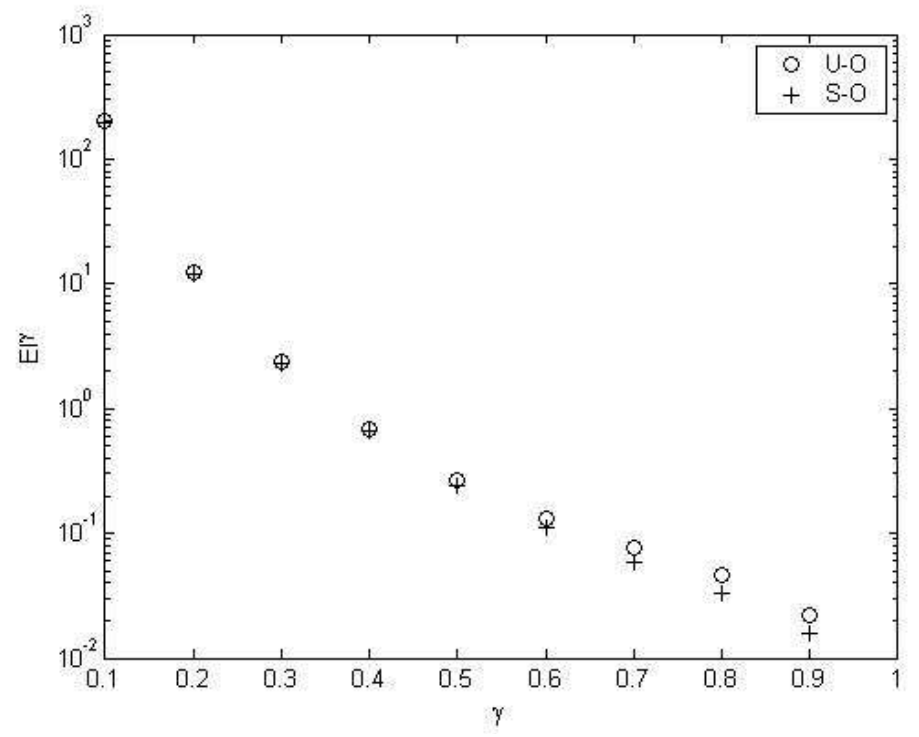

Figure 3: Plot of $\mathrm{EI}_{U-O}^{\gamma}$ and $\mathrm{EI}_{S-O}^{\gamma}$ for the Yin and Lawphongpanich (2006) Network 
As can be seen from Table 3 and Figure 2, the total emissions generated are lower under the U-O behavioral principle from $\gamma=1$ (this case was noted also by Yin and Lawphongpanich (2006)) until $\gamma=.7$. For $\gamma=.7, .6$, and so on, through $\gamma=.1$ the total emissions generated under $\mathrm{S}-\mathrm{O}$ behavior are lower than those generated under U-O behavior. However, once $\gamma=.3$ the difference is not appreciable. One can easily see from Table 5 and Figure 3, in turn, that, under S-O behavior, the transportation network may be viewed as being more robust from an environmental perspective in that, for a given value of $\gamma$ that is less than 1, the value for $\mathrm{S}-\mathrm{O}$ is lower than the value for $\mathrm{U}-\mathrm{O}$ indicating that the relative increase in emissions for this example is lower when the transportation network link capacities decrease in the case of $\mathrm{S}-\mathrm{O}$ behavior.

We now proceed to determine the link importance indicators according to (8a) and (8b). The results are reported in Tables 4 and 5, respectively. In Figure 4, we display the importance indicator values and the rankings of the links from most important to least important under both U-O and S-O behaviors. It is clear from Figure 4 that the rankings of the links are identical for this numerical example when the travelers behave in either a $\mathrm{U}-\mathrm{O}$ or in a S-O manner. In particular, link $b$ is most important, followed by link $a$, and then link $d$. Links $c$ and $f$ are equal in importance followed by links $e$ and $g$, which also share the same importance indicator value. Hence, from an environmental planning/maintenance/security perspective, the links should be "protected" accordingly.

Table 4: Link Importance Indicators Under U-O Behavior for the Yin and Lawphongpanich (2006) Network

\begin{tabular}{|c|c|c|}
\hline Link $l$ & $\mathrm{TE}_{U-O}(G-l)$ & $\mathrm{I}_{U-O}^{l}$ \\
\hline$a$ & 30439.95 & 0.14 \\
$b$ & 31823.13 & 0.19 \\
$c$ & 27802.31 & 0.04 \\
$d$ & 28752.22 & 0.07 \\
$e$ & 27692.11 & 0.03 \\
$f$ & 27802.31 & 0.04 \\
$g$ & 27692.11 & 0.03 \\
\hline
\end{tabular}


Table 5: Link Importance Indicators Under S-O Behavior for the Yin and Lawphongpanich (2006) Network

\begin{tabular}{|c|c|c|}
\hline Link $l$ & $\mathrm{TE}_{S-O}(G-l)$ & $\mathrm{I}_{S-O}^{l}$ \\
\hline$a$ & 30493.30 & 0.12 \\
$b$ & 31856.33 & 0.17 \\
$c$ & 28070.21 & 0.03 \\
$d$ & 28752.22 & 0.06 \\
$e$ & 27909.01 & 0.03 \\
$f$ & 28070.21 & 0.03 \\
$g$ & 27909.01 & 0.03 \\
\hline
\end{tabular}

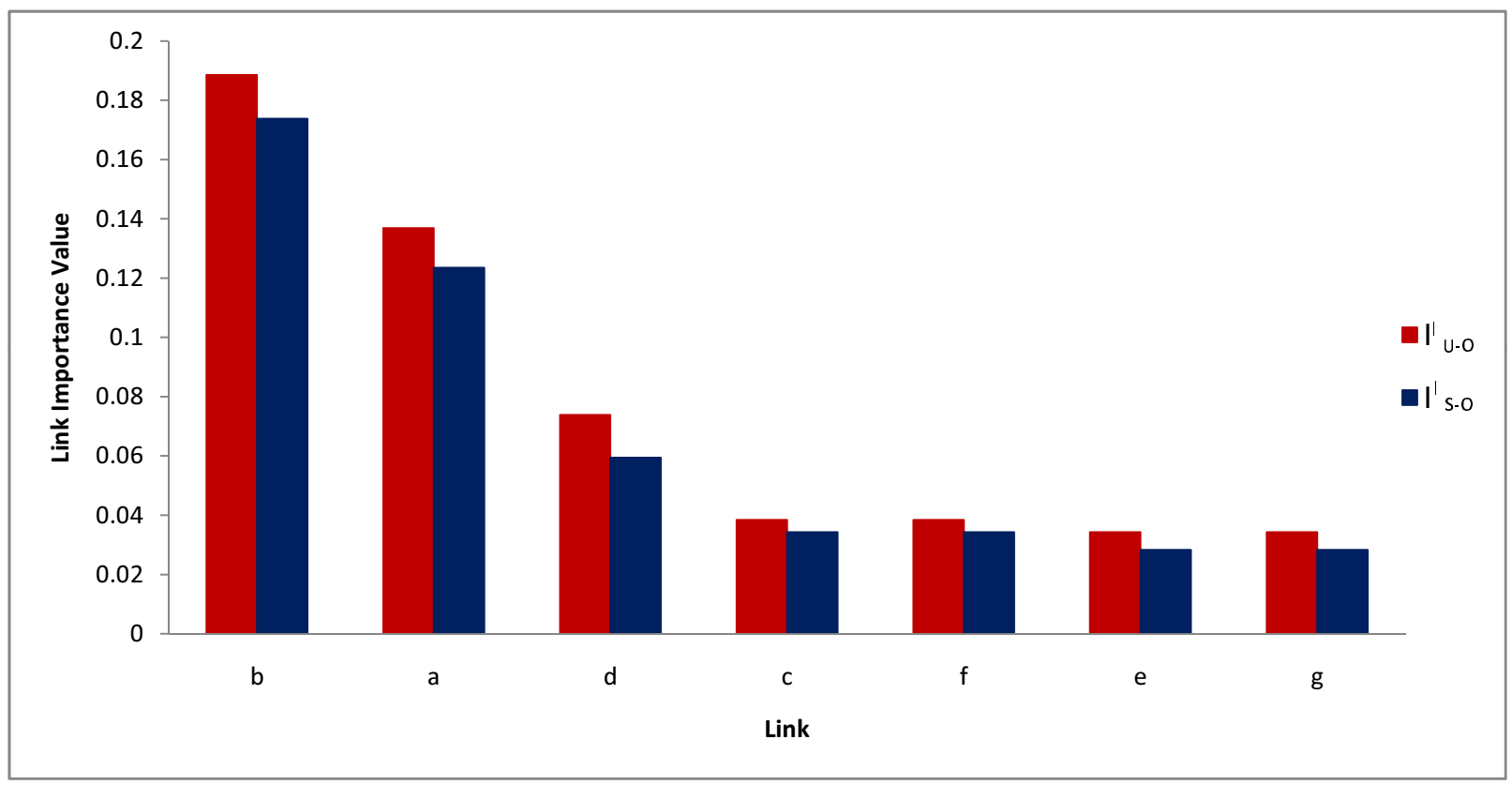

Figure 4: Link Importance Values and Rankings Under U-O and S-O Behavior for the Yin and Lawphongpanich (2006) Network 


\subsection{The Sioux Falls Network}

We now consider the Sioux Falls network (cf. LeBlanc, Morlok, and Pierskalla (1975)). The network topology is shown in Figure 5.

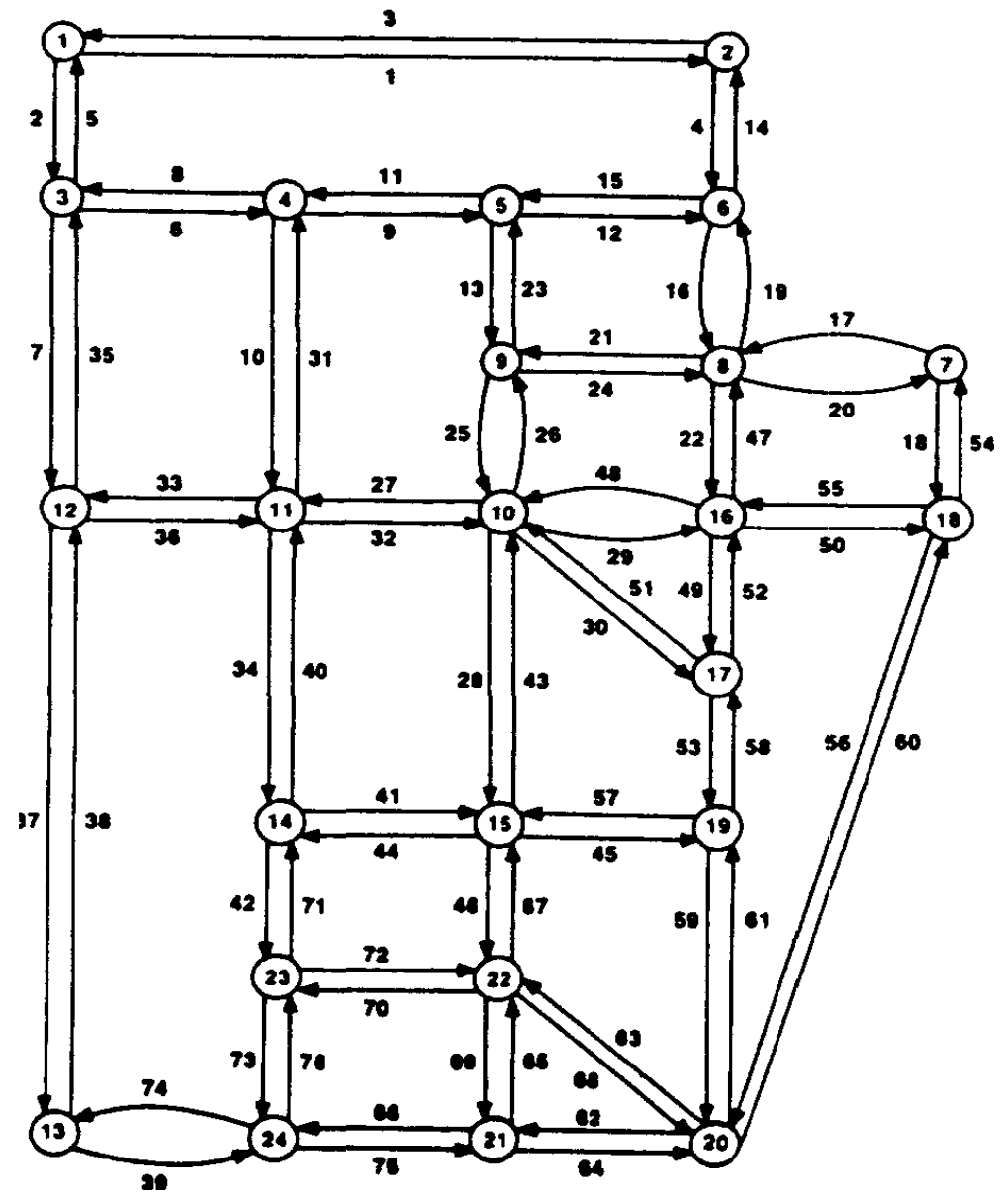

Figure 5: The Sioux Falls Network (Friesz et al., 1994)

There are 24 nodes, 76 links, and 528 O/D pairs in the Sioux-Falls network. For the relevant data see LeBlanc, Morlok, and Pierskalla (1975) and the transportation network datasets maintained by Bar-Gera: http://www.bgu.ac.il/ bargera/tntp/.

In Table 6, we present the total CO emissions generated under these two distinct behavioral assumptions and under the same capacity retention ratios $\gamma$. In addition, Table 6 also documents the two environmental impact assessment indices.

In Figure 6, we depict the ratio of $\mathrm{TE}_{U-O}^{\gamma}$ to $\mathrm{TE}_{S-O}^{\gamma}$. In Figure 7, we plot the ratio of $\mathrm{EI}_{U-O}^{\gamma}$ to $\mathrm{EI}^{\gamma}{ }_{S-O}$. 
Table 6: Total Emissions Generated (grams/hour) and Environmental Impact Indicators for Varying Degradable Capacities for the Sioux Falls Network

\begin{tabular}{|c|c|c|c|c|}
\hline$\gamma$ & $\mathrm{TE}_{U-O}^{\gamma}\left(\times 10^{6}\right)$ & $\mathrm{EI}_{U-O}^{\gamma}$ & $\mathrm{TE}_{S-O}^{\gamma}\left(\times 10^{6}\right)$ & $\mathrm{EI}_{S-O}^{\gamma}$ \\
\hline 1. & 2.2323 & .0000 & 5.2578 & .0000 \\
.9 & 2.5964 & .1636 & 7.2030 & .3700 \\
.8 & 3.2447 & .4542 & 10.6592 & 1.0273 \\
.7 & 4.4820 & 1.0087 & 17.2023 & 2.2717 \\
.6 & 7.0677 & 2.1675 & 30.7401 & 4.8466 \\
.5 & 13.1320 & 4.8854 & 62.3732 & 10.8631 \\
.4 & 30.0623 & 12.4720 & 150.5202 & 27.6279 \\
.3 & 92.0500 & 40.2540 & 473.1643 & 88.9920 \\
.2 & 460.5401 & 205.3999 & 2390.7321 & 453.6959 \\
.1 & 7348.6102 & 3292.4000 & 38235.1022 & 7271.0529 \\
\hline
\end{tabular}

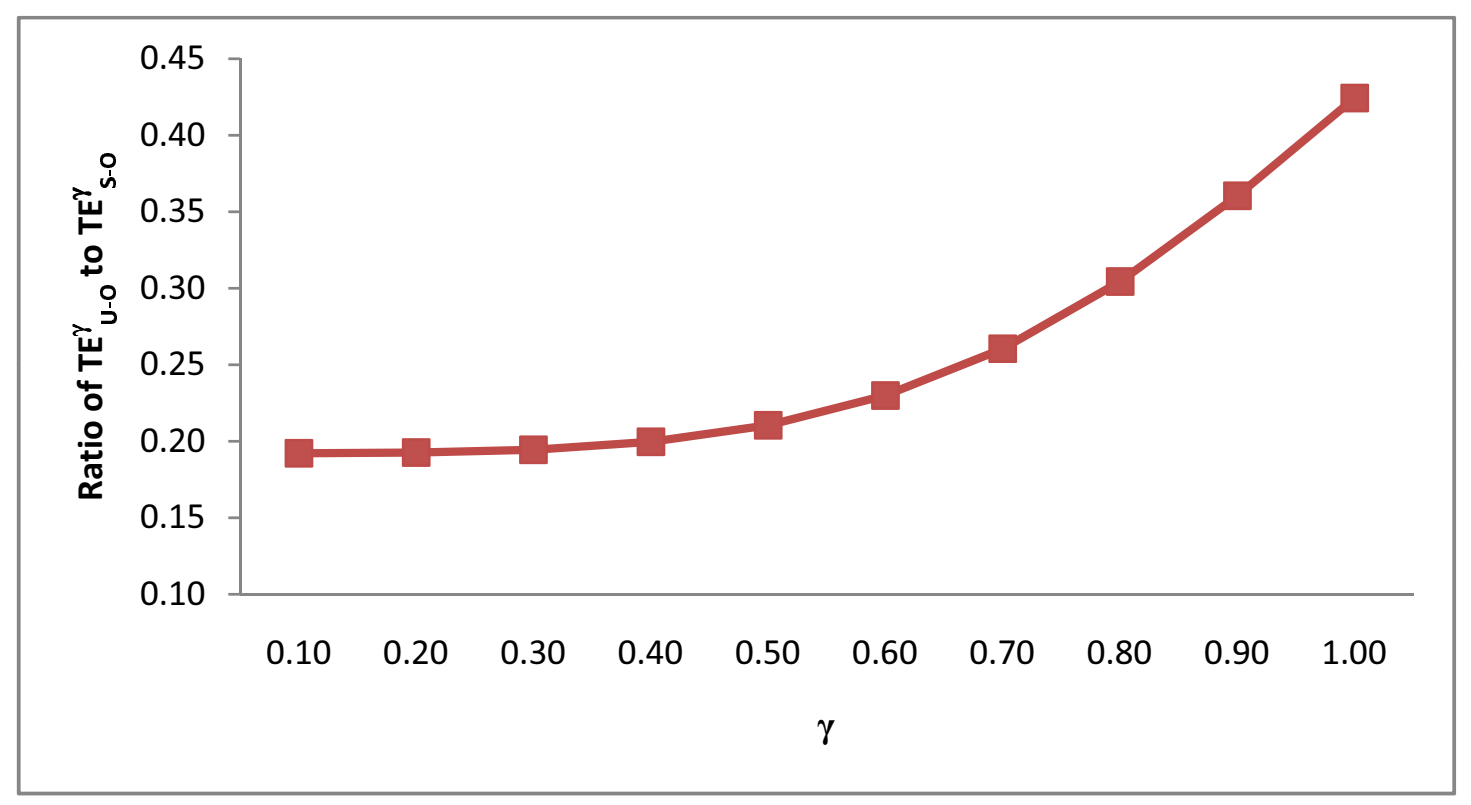

Figure 6: Ratio of $\mathrm{TE}_{U-O}^{\gamma}$ to $\mathrm{TE}_{S-O}^{\gamma}$ for the Sioux Falls Network 


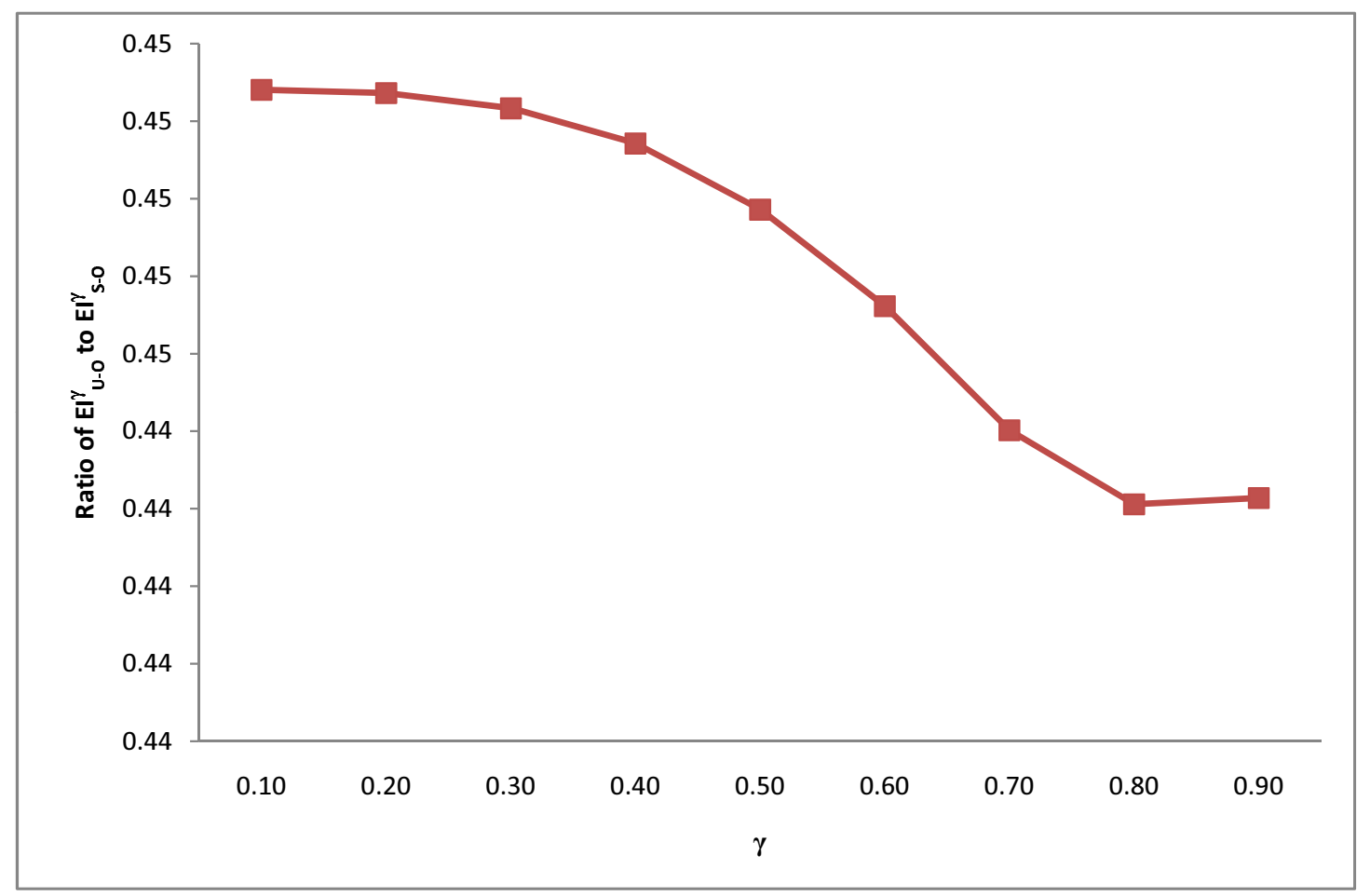

Figure 7: Ratio of $\mathrm{EI}_{U-O}^{\gamma}$ to $\mathrm{EI}_{S-O}^{\gamma}$ for the Sioux Falls Network

As can be seen from Table 6 and Figure 6, the total emissions generated under the UO behavioral principle are consistently lower than those under S-O behavior. Moreover, the difference gets larger with an increase in the capacity retention ratio $\gamma$. One can also easily see from Table 6 and Figure 7, in turn, that, under U-O behavior, the transportation network may be viewed as being more robust from an environmental perspective in that, for a given value of $\gamma$ that is less than 1, the value for $\mathrm{U}-\mathrm{O}$ is lower than the value for S-O indicating that the relative increase in emissions for Sioux-Falls network is lower when the transportation network link capacities decrease in the case of U-O behavior. This result is different from that of Example 1 since the network topology as well as the cost and demand information are different. Therefore, we have to study networks individually and the associated travel behavior in order to evaluate the environmental impacts, in the case of network link degradation. 


\section{Summary, Conclusions, and Suggestions for Future Research}

In this paper, we proposed environmental impact assessment indicators that allow one to determine the environmental impacts of the degradation in transportation network link capacities. The proposed indicators can evaluate the impacts associated with either U-O behavior or S-O behavior. We illustrated through numerical examples that there may be ranges of link capacity deterioration for which U-O behavior yields lower emissions than S-O behavior and vice versa. We also proposed link importance indicators that allow for the evaluation of the impact on environmental emissions if a link deteriorates to such a degree that it is no longer usable. For a particular transportation network example, we showed that the link importance rankings were identical in the case of $\mathrm{U}-\mathrm{O}$ and $\mathrm{S}-\mathrm{O}$ behaviors.

With this paper, we hope to promote a new research agenda into the determination of quantitative measures associated with transportation networks, environmental vulnerability and robustness analysis, and climate change. Further research should include the extension of the results in this paper to multimodal transportation networks and multiple pollutants as well as theoretical and computational sensitivity analysis studies. In addition, it would be interesting to investigate the case of elastic demands. 


\section{Acknowledgments}

This research of the first and second authors was supported by the John F. Smith Memorial Fund at the University of Massachusetts at Amherst. This support is gratefully appreciated.

The authors acknowledge the helpful comments and suggestions of four anonymous reviewers on an earlier version of this paper.

\section{References}

Akcelik, R., Besley, M., 2003. Operating cost, fuel consumption, and emission models in aaSIDRA and aaMOTION. In 25th Conference of Australian Institutes of Transport Research (CAITR 2003), University of South Australia, Adelaide, Australia, December 3-5, 2003.

Alexopoulos, A., Assimacopoulos, D., 1993. Model for traffic emissions estimation. Atmospheric Environment 27B, 435-466.

American Society of Civil Engineers, 2005. Report card for America's infrastructure.

Arkell, B. P., Darch, G. J. C., 2006. Impact of climate change on London's transport network. Municipal Engineer 4, 231-237.

Bazaraa, M. S, Sherali, H. D., Shetty, C. M., 1993. Nonlinear programming: theory and algorithms. John Wiley \& Sons, New York.

Beckmann, M. J., McGuire, C. B., Winsten, C. B., 1956. Studies in the economics of transportation. Yale University Press, New Haven, Connecticut.

Berdica, K., 2002. An introduction to road vulnerability: What has been done, is done and should be done. Transport Policy 9, 117-127.

Boyce, D. E., Mahmassani, H. S., Nagurney, A., 2005. A retrospective on Beckmann, McGuire and Winsten's Studies in the economics of transportation. Papers in Regional Science 84, 85-103.

Bureau of Public Roads, 1964. Traffic assignment manual, US Department of Commerce, Washington, DC.

California Air Resource Board, 2005. Methods to find the cost-effectiveness of funding air quality projects.

http://www.arb.ca.gov/planning/tsaq/eval/mv_fees_cost-effectiveness_methods_may05.pdf. 
Dafermos, S., 1980. Traffic equilibrium and variational inequalities. Transportation Science $14,42-54$.

Dafermos, S. C., Sparrow, F. T., 1969. The traffic assignment problem for a general network. Journal of Research of the National Bureau of Standards 73B, 91-118.

Friesz, T. L., David, B., Mehta, N. J., Tobin, R. L., Ganjalizadeh, S., 1994. Day-to-day dynamic network disequilibria and idealized traveler information systems. Operations Research 42, 1120-1136.

Hizir, A. E., 2006. Using emission functions in mathematical programming models for sustainable urban transportation: An application in bilevel optimization, Master of Science Dissertation, Sabanci University, Turkey.

Jeanneret, M., 2006. Federal government freight bottleneck report highlights America's growing transportation infrastructure crisis; http://artba.com/news/press_releases/2006/0203-06.htm

Jenelius, E., 2007. Approaches to road network vulnerability analysis, Licentiate thesis in infrastructure, Royal Institute of Technology, Stockholm, Sweden.

LeBlanc, L. J., Morlok, E. K., and Pierskalla, W. P., 1975. An efficient approach to solving the road network equilibrium traffic assignment problem. Transportation Research $B$ 9, 309-318.

Murray, A. T., Grubesic, T. H., editors, 2007. Critical infrastructure: Reliability and vulnerability. Springer, Berlin, Germany.

Nagurney, A., 1999. Network economics: a variational inequality approach (2nd edition). Kluwer Academic Publishers, Dordrecht, The Netherlands.

Nagurney, A., 2000a. Sustainable transportation networks. Edward Elgar Publishing, Cheltenham, England.

Nagurney, A., 2000b. Congested urban transportation networks and emission paradoxes. Transportation Research D 5, 145-151.

Nagurney, A., Qiang, Q., 2007a. A network efficiency measure for congested networks. Europhysics Letters 79, 38005, pp 1-5.

Nagurney, A., Qiang, Q., 2007b. Robustness of transportation networks subject to degradable links. Europhysics Letters 80, 68001, pp 1-6. 
Nagurney, A., Qiang, Q., 2007c. A transportation network efficiency measure that captures flows, behavior, and costs with applications to network component importance identification and vulnerability, in Proceedings of the POMS 18th Annual Conference, Dallas, Texas.

Nagurney, A., Qiang, Q., 2008. A relative total cost index for the evaluation of transportation network robustness in the presence of degradable links and alternative travel behavior, International Transactions in Operational Research 16, 49-67.

National Assessment Synthesis Team, 2001. Climate change impacts on the United States, US Global Change Research Program; http://www.usgcrp/usgcrp/Library/national assessment/overviewnortheast.htm

Rilett, L. R., Benedek, C. M., 1994. Traffic assignment under environmental and equity objective. Transportation Research Record 1443, 92-99.

Sakakibara, H., Kajitani, Y., Okada, N., 2004. Road network robustness for avoiding functional isolation in disasters. Journal of Transportation Engineering 130, 560-567.

Scott, D. M., Novak, D., Aultman-Hall, L., Guo, F., 2006. Network robustness index: a new method for identifying critical links and evaluating the performance of transportation networks. Journal of Transport Geography 14, 215-227.

Schulz, C., 2007. Identification of critical transportation infrastructures. Forum DKKV/CEDM, Disaster Reduction in Climate Change, Karlsruhe University, Germany.

Sheffi, Y., 1985. Urban transportation networks - equilibrium analysis with mathematical programming methods. Prentice-Hall, Englewood Cliffs, New Jersey.

Smith, M., 1979. Existence, uniqueness, and stability of traffic equilibria. Transportation Research B 13, 259-304.

Smith, O. P., Levasseur, G., 2002. Impacts of climate change on transportation infrastructure in Alaska; http://www.climate.dot.gov/workshop1002/smith.doc

Sugawara, S., Niemeier, D. A., 2002. How much can vehicle emissions be reduced? Transportation Research Record 1815, 29-37.

Taylor, M. A. P., Anderson, M. 1984. Energy and emissions in a metropolitan road transport system. Proceedings of 12th Australian Road Research Board Conference 12, 63 - 78.

Taylor, M. A. P., Sekhar, S. V. C., and D'Este, G. M., 2006. Application of accessibility based methods for vulnerability analysis of strategic road networks. Networks and Spatial 
Economics 6, 267-291.

US EPA, 2006. Greenhouse gas emissions from the U. S. transportation section: 1990-2003; http://www.epa.gov/oms/climate/420r06003summary.htm

US Department of Transportation, 2002. The potential impacts of climate change on transportation. Workshop summary and proceedings; http://climate.dot.gov/workshop1002.index.html

US Department of Transportation Federal Highway Administration, 2006a. An initial assessment of freight bottlenecks on highways, Washington, DC.

US Department of Transportation Federal Highway Administration, 2006b. Air quality fact book. Publication No. FHWA-HEP-05-045 HEP/12-05(8M)E, Washington, DC.

Wallace, C. E., Courage, K. G., Hadi, M. A., Gan, A. G., 1998. TRANSYT-7F user's guide. University of Florida, Gainesville.

Wardrop, J. G., 1952. Some theoretical aspects of road traffic research. Proceedings of the Institution of Civil Engineers, Part II 1,325-378.

Wigan, M. R., 1975. The estimation of environmental impacts for transport policy assessment. Environment and Planning A 8, 125 - 147.

Yin, Y., Lawphongpanich, L., 2006. Internalizing emission externality on road networks. Transportation Research D 11, 292-301.

Zimmerman, R., 2003. Global climate change and transportation infrastructure: lessons from the New York area, in The potential impacts of climate change on transportation: Workshop summary and proceedings, Washington, DC: US DOT, pp. 91-101. 